The skeletal remains of infants and children are a poignant reminder of the perilous nature of childhood in the past, yet they offer valuable insight into the life histories of individuals and into the health of populations. Many osteoarchaeological and bioarchaeological analyses are dependent on two vital pieces of information: the age-at-death and sex of the individual(s) under study. This chapter will outline how age-at-death and sex can be estimated from the skeletal remains and dentition of non-adults and will discuss the complexities and controversies surrounding different methods. While age estimation of (relatively compete) non-adult skeletons produces accurate and precise results, sex assessment is fraught with difficulties due to low levels of sexual dimorphism in immature skeletal remains.

osteoarchaeology, bioarchaeology, age estimation, puberty, tooth formation, skeletal development, sex assessment

3.

\title{
Techniques for Identifying the Age and Sex of Children
}

\section{at Death}

\section{Jo Buckberry}

The skeletal remains of infants and children are a poignant reminder of the perilous nature of childhood in the past, yet they offer valuable insight into 
the life histories of individuals and into the health of populations. Many osteoarchaeological and bioarchaeological analyses are dependent on two vital pieces of information: the age and sex of the individual(s) under study. This chapter will outline how age and sex can be estimated from the skeletal remains of non-adults and will discuss the complexities and controversies surrounding different methods.

\section{Biological identity}

Human osteoarchaeologists use observed differences on skeletons to make inferences about the biological status of an individual. The methods used rely, to a certain extent, on the principle of uniformitarianism, meaning that if observation $\mathrm{X}$ correlates with age (or sex) $\mathrm{Y}$ in modern individuals, then if we see observation $\mathrm{X}$ in archaeological remains, the individual is probably of age (or sex) Y. Of course, the reality is much more complex. Many of the features observed on skeletal remains do not directly correlate to a specific age or sex; rather certain traits are more commonly observed in males, or the average age of attainment of a specific developmental stage is a certain age, but individuals will vary around these 'ideals'. Osteologists combine data to produce age estimates and sex assessments ${ }^{1}$, and methods are regularly tested to investigate ease of application, repeatability, accuracy, and variation between populations. 
For age estimation, many methods rely on clinical data pertaining to the mean age of attainment of a specific stage, and the standard deviation and range of ages seen around this point. Growth-related studies usually record the average height or bone size of a certain age group, data that can be used to estimate age based on the average measurements of an age cohort. Care should be taken to consider the variation about the mean, which is typically much smaller when dealing with non-adult age in comparison to adult age estimates. The range of variation seen for some observations has led to the comparison of biological age (non-linear maturation stages) rather than chronological age (the linear passing of time since an individual's birth) and can be used to investigate social age (Buikstra and Ubelaker 1994; Cox 2000). Studies of modern populations of different socioeconomic statuses have shown that children with poor access to resources are likely to grow and develop at a slower rate than their wealthier and/or healthier counterparts (Lewis and Garn 1960). Empirical observation has shown that certain aspects of development are more likely to be influenced by external factors; thus, osteoarchaeologists will rely on methods shown to be more resistant to these external factors, such as dental development and, to a lesser extent, dental eruption, as will be shown later.

Sex assessment of non-adults is a much more controversial topic than age estimation; the observed differences between males and females 
are typically quite small (resulting in greater inter- and intra-observer error) and accuracy levels for published methods are typically much lower for non-adults than for adults. Many osteologists prefer not to assess the sex of non-adults due to these lower accuracy levels, but doing so makes it impossible to investigate the different life (and death) experiences of boys and girls.

\section{Estimating age-at-death}

Estimating non-adult age-at-death is less problematic than estimating adult age-at-death, as the growth and development of bones and teeth occur in a fairly regular and well understood sequence. This allows the ages of children to be estimated with fairly high degrees of accuracy and precision, providing their skeletons are complete and not fragmentary. Naturally, the accuracy of an age estimate will decrease considerably for skeletons missing important elements, particularly the dentition. Many studies have shown that there is some variation in the timing of developmental stages between the sexes, with girls generally more advanced than boys of the same age, particularly during puberty. As discussed below, sex assessment of non-adults is controversial; if sex is not assessed then age estimates for males and females must be combined, producing wider age ranges (Scheuer and Black 2000a). Non-adult age-at-death can be estimated using the 
formation and eruption of the dentition, and the growth and fusion of bones.

Individual age estimates are typically given as an estimated age range (e.g. two to four years), rather than point age estimates (e.g. 2.5 years) to reflect variability in age estimates from different areas of the same skeleton, and variation in the age at which different individuals reach the level of maturation seen. Comparisons are often made between different populations, or subgroups of the same population, using age groups. However, the age groups used vary between researchers, which can make comparison of different datasets difficult (Crawford 1991: 19-20; see Table 3.1). Indeed, it has been argued that the names used for many age categories (e.g. infant, child, juvenile) have specific meanings in different social contexts and thus are culturally loaded (Gowland 2006: 144).

Table 3.1: Comparisons of stages of development and associated age ranges. Data taken from Lewis (2007: 2, Table 1.1), and Scheuer and Black (2000a: 10, Table 1).

\begin{tabular}{|l|l|l|}
\hline & $\begin{array}{l}\text { Scheuer and Black } \\
(\mathbf{2 0 0 0 a})\end{array}$ & Lewis (2007) \\
\hline Embryo & First 2 months in utero & First 8 weeks in utero \\
\hline Foetus & Third month to birth & $\begin{array}{l}\text { 8 weeks in utero until } \\
\text { birth (c.38 weeks) }\end{array}$ \\
\hline
\end{tabular}




\begin{tabular}{|c|c|c|c|}
\hline \multicolumn{2}{|c|}{ Perinate } & $\begin{array}{l}\text { Around the time of } \\
\text { birth }\end{array}$ & $\begin{array}{l}\text { Around birth-24 } \\
\text { weeks gestation to } 7 \\
\text { post-natal days` }\end{array}$ \\
\hline \multicolumn{2}{|c|}{ Neonate } & $\begin{array}{l}\text { Birth to the end of the } \\
\text { first month }\end{array}$ & $\begin{array}{l}\text { Birth to } 27 \text { post-natal } \\
\text { days }\end{array}$ \\
\hline \multicolumn{2}{|l|}{ Infant } & $\begin{array}{l}\text { Birth to the end of the } \\
\text { first year` }\end{array}$ & Birth to one year \\
\hline \multirow[t]{2}{*}{ Child } & $\begin{array}{l}\text { Young } \\
\text { child }\end{array}$ & $\begin{array}{l}\text { To the end of the fifth } \\
\text { year }\end{array}$ & \multirow[t]{2}{*}{1 to 14.6 years } \\
\hline & Old child & $\begin{array}{l}\text { About } 6 \text { years to } \\
\text { puberty }\end{array}$ & \\
\hline \multicolumn{2}{|c|}{ Adolescent } & - & 14.6 to 17 years \\
\hline \multicolumn{2}{|c|}{ Non-adult } & - & $\leq 17$ years \\
\hline
\end{tabular}

\section{Estimating age-at-death from the dentition}

Humans have two sets of teeth. Deciduous teeth start to develop in utero, erupt by age two to three years, and are exfoliated during older childhood (c.five to 12 years); most humans develop 20 deciduous teeth, which are replaced by (usually) 32 permanent teeth. The first permanent teeth to start developing are the first molars, which start to form in dental crypts distal to the deciduous molars in utero. The anterior permanent teeth develop in crypts above/below the corresponding maxillary/mandibular deciduous teeth; as the crowns develop the roots of the deciduous teeth resorb until the deciduous teeth are exfoliated, at which point the permanent teeth can 
erupt. Permanent molars are not preceded by deciduous teeth but develop in the same way before erupting into the mouth. In skeletal remains, age-atdeath can be estimated by looking at the level of formation of teeth, the eruption of teeth relative to the alveolar bone, the resorbtion of deciduous teeth, or a combination of these (AlQahtani, Hector, and Liversidge 2010).

\section{Tooth formation}

The mineralization of dental enamel and dentine follows a well-understood sequential pattern (Whittaker 2000), is genetically controlled, and is little affected by external environmental factors (Lewis and Garn 1960; Elamin and Liversidge 2013). This makes tooth formation the most reliable indicator of non-adult age (Smith 1991; Scheuer and Black 2000a; Mays 2010).

Teeth are formed in crypts within the alveolar bone. The teeth develop initially from the enamel-dentine junction. Enamel forms towards the occlusal (biting) surface, dentine towards the root with the sides of the crown then growing to form the complete enamel cap. Root growth continues with the formation of dentine and cementum at a regular rate that completes with closure of the root apex. Eruption usually occurs one to two years prior to the completion of root development (Hillson 1996). These stages can be observed macroscopically on loose teeth and radiographically for teeth embedded within jaws (Figure 3.1). All but the earliest stages can 
be seen in archaeological individuals. These stages of tooth formation have been recorded in living children, and ages of attainment of the different stages for deciduous and permanent teeth have been recorded (Smith 1991). Many studies have been undertaken, utilizing populations around the world, and variation in the rate of maturation and development of teeth in different populations have been observed (see Lewis 2007: 40), but development does not appear to be affected by malnutrition (Elamin and Liversidge 2013).

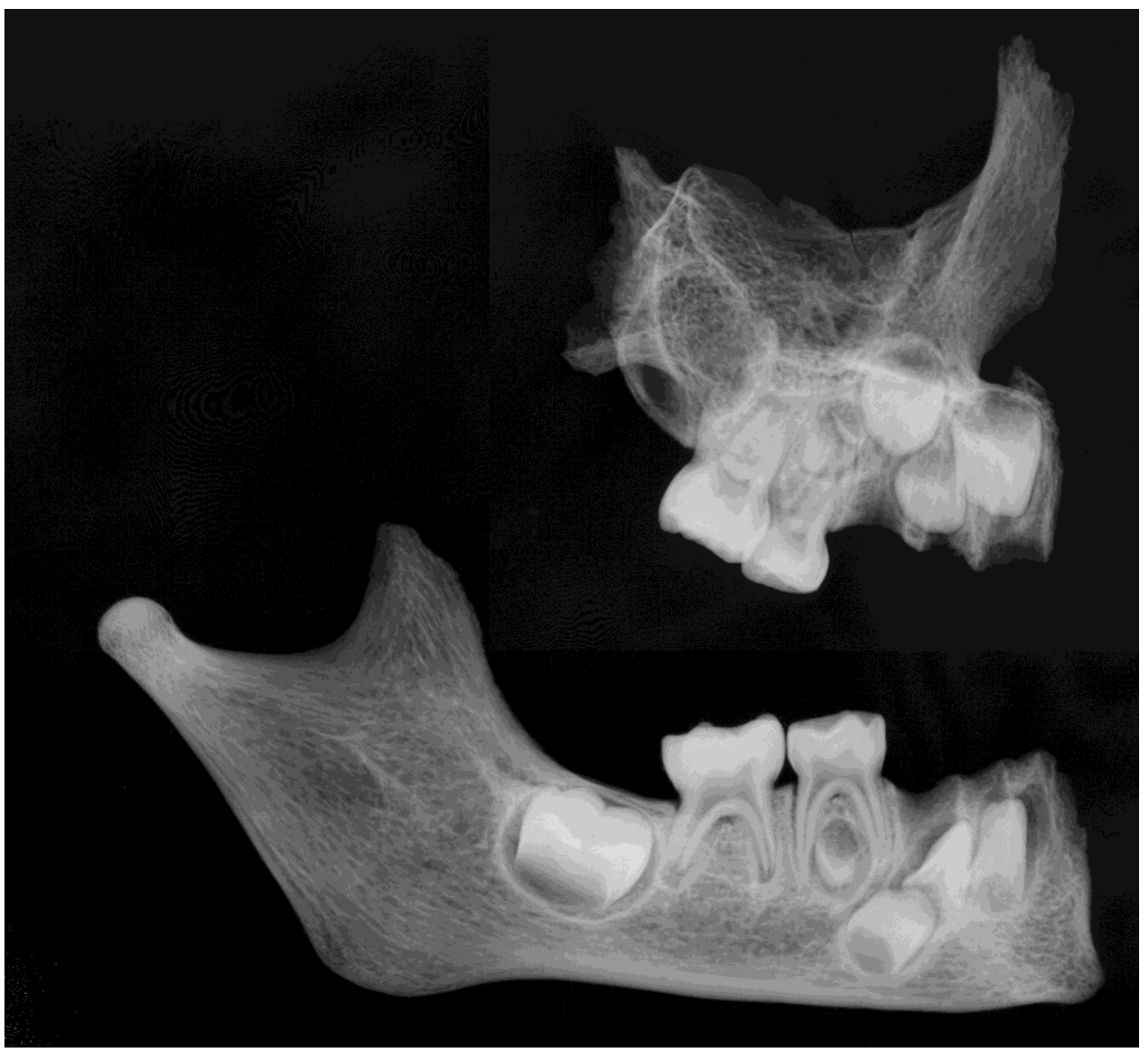


Figure 3.1. Radiograph of the jaws of a c. three year old. The deciduous molars are erupted, but the roots of M2 have not finished developing. The anterior deciduous teeth have been lost post-mortem. Developing teeth can be seen in the dental crypts, but the second permanent molars have not yet initiated formation. (C) BARC, Archaeological Sciences, University of Bradford.

The standards published by Coenraad Moorrees and colleagues $(1963 a, b)$ for assessing age based on the formation of teeth are considered by many to be the most accurate, as their sample population included many younger individuals, thus not truncating the lower age ranges (Smith 1991). Usefully, each tooth can be assessed independently, although combining the ages for several teeth increases accuracy in age estimation (Moorrees, Fanning, and Hunt $1963 a, b)$. Girls were found to be more advanced than males throughout the sequence of development, although this was less marked for the deciduous dentition (Smith 1991; Hillson 1996). B. Holly Smith (1991) reworked the data collected by Moorrees and colleagues for permanent teeth to make it more suitable for age estimation (rather than for assessing dental maturity), presenting the mean age of attainment for each stage for males and females in tables. The Smith (1991) method was found to be substantially more accurate for age estimation than the original 
Moorrees, Fanning, and Hunt (1963a) method when applied to the Christ Church, Spitalfields, known-age collection (Liversidge 1994). In contrast, testing on the Belleville, Ontario, known-age sample (Saunders et al. 1993) revealed that the unmodified Moorrees, Fanning, and Hunt (1963a) method for permanent teeth was more accurate than that of Smith (1991).

Other standards of dental development have also been developed. The Anderson, Thompson, and Popovitch (1976) method was found to overestimate the age of young children, probably due to the lack of individuals in the reference sample under three years of age (Saunders et al. 1993). The applicability of the Demirjian and colleagues (1973) method of age estimation has been criticized for use with archaeological material as it does not allow for missing teeth (Hillson 1996). Their four-tooth systems (Demirjian and Goldstein 1976), however, can be applied to archaeological samples, providing the correct four teeth $\left(\mathrm{M}_{2}, \mathrm{M}_{1}, \mathrm{PM}_{2}, \mathrm{PM}_{1}\right.$ or $\mathrm{M}_{2}, \mathrm{PM}_{2}$, $\left.\mathrm{PM}_{1} \mathrm{I}_{1}\right)^{2}$ are present.

\section{Dental eruption}

Dental eruption refers to the process where teeth migrate from within the jaw, through the alveolar bone and gums, to the occlusal plane. This process continues throughout life, compensating for occlusal wear or loss of the opposing teeth (Hillson 1996; Scheuer and Black 2000b). Clinical or gingival eruption refers to the appearance of teeth through the gums. This 
stage of development cannot be assessed on archaeological skeletons; however, eruption through the alveolar bone and the entry of the crown onto the occlusal plane can be recorded (Hillson 1996).

Most clinical studies of dental eruption are based on gingival eruption, and have shown that both the timing and sequence can be variable both within and between populations (Hillson 1996), with eruption generally occurring later for those from a lower socioeconomic background (Garn et al. 1973). In addition, dental eruption can be affected by caries, premature tooth loss, and malnutrition (Smith 1991). Despite these problems, dental eruption is frequently used to assess non-adult age, particularly when used in combination with data regarding dental development, usually presented in atlas form.

\section{Dental atlases}

Data regarding dental development and dental eruption can be combined visually into a dental atlas. Many osteologists use the dental chart produced by Douglas Ubelaker (1989), which is based on the dental atlas of Isaac Schour and Maury Massler (1941), but modified to acknowledge differences in dental eruption seen in Native American populations (Ubelaker 1989; Buikstra and Ubelaker 1994; Hillson 1996). More recently, the London Dental Atlas has combined and compared data from 704 individuals, comprising skeletal remains under two years of age $(\mathrm{n}=$ 
176) and radiographs of individuals aged two to 28 years $(\mathrm{n}=528)$, a much larger sample size than used in previous studies. The resultant atlas has increased detail and information for the older stages of dental development, yet maintains the level of detail seen for younger individuals in earlier charts. By using equal numbers of individuals in each age cohort, it reduces the risk of the reference population structure skewing resultant age estimates. A recent test has found better accuracy for the London Dental Atlas when compared to Schour and Massler (1941) and Ubelaker (1989); however all three methods tended to underage older individuals (AlQahtani, Hector, and Liversidge 2014).

\section{Skeletal development}

Most of the major bones of the body begin to ossify during foetal life, although the primary ossification centres of some smaller bones, including the carpals and tarsals, start to ossify during infancy and childhood (Mays 2010). Secondary ossification centres form as separate bones and fuse to the primary centres during development; these are called epiphyses (which relate to joints) and apophyses (which relate to muscle attachments). Epiphyses and apophyses are separated from the rest of the bone by cartilaginous growth plates, which allow bones to grow rapidly without having to continually remodel articular surfaces and other structures. During development, bones fuse together and, in the case of long bones 
(which fuse during adolescence), terminate longitudinal growth and hence increase in stature (Ubelaker 1989; Mays 2010). As these fusion events occur sequentially, epiphyseal and apophyseal fusion can be used to estimate non-adult age, particularly during early childhood, when the vertebrae fuse, and during adolescence when fusion of the long bones occurs. The timing of epiphyseal fusion varies between the sexes, with union generally occurring in females one to two years before males (Ubelaker 1989). If sex is not assessed for non-adult remains, it is necessary to combine the age ranges for both sexes for the timing of each fusion event. Many publications detail the age at which different fusion events occur, some giving great detail about a specific bone or group of bones (e.g. Redfield 1970; Weaver 1979) and others giving a broad overview of fusing of the major epiphyses (e.g. Ubelaker 1989; Buikstra and Ubelaker 1994; Schaefer 2008; Mays 2010). Probably the most comprehensive discussion was by Louise Scheuer and Sue Black (2000b), where the data is combined with the age at which ossification centres appear ( Figures 3.2 and 3.3). 


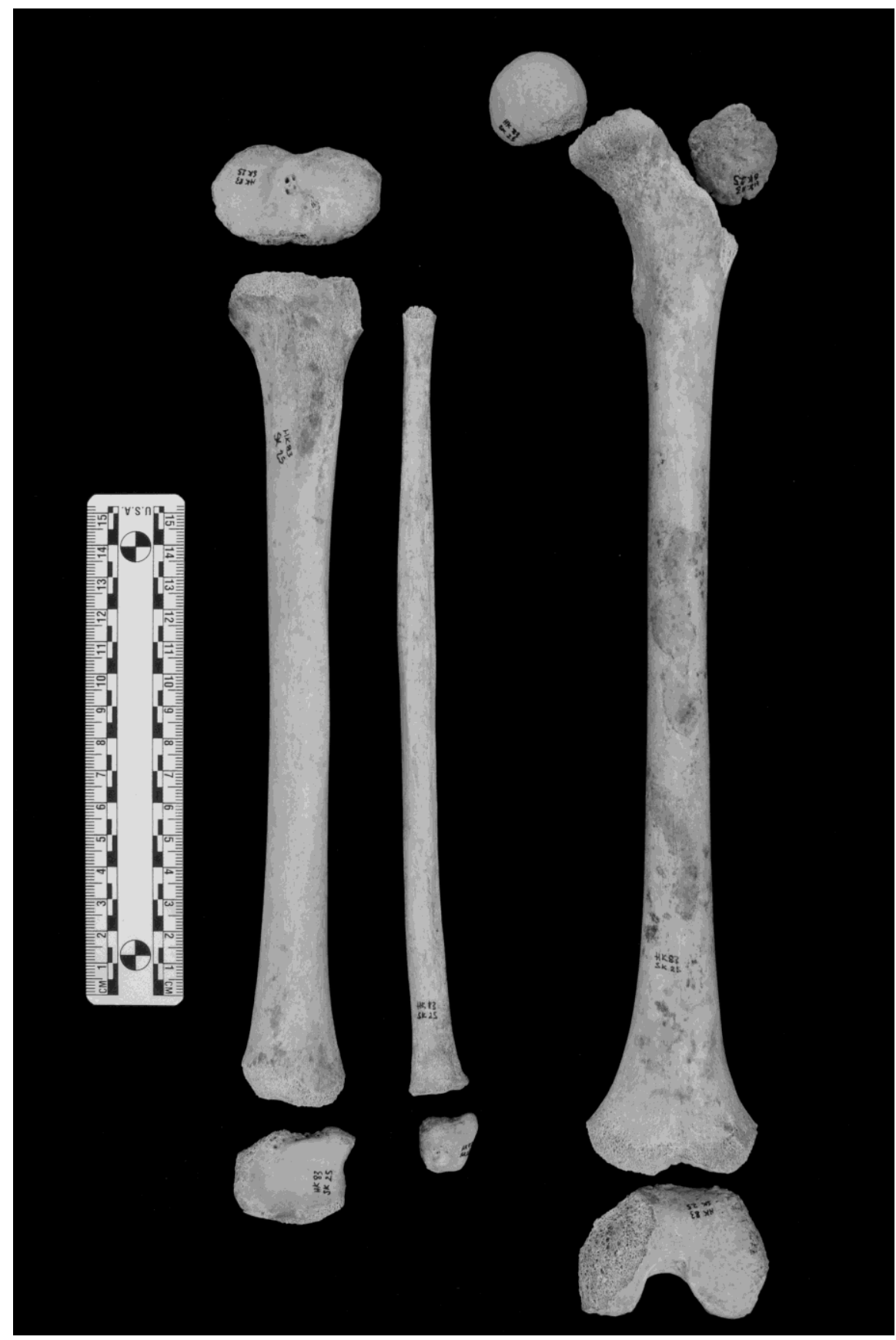

Figure 3.2. Femur, tibia and fibula of a seven to eight year old. The epiphyses have not fused; the proximal epiphysis of the fibula was not recovered at excavation. (C) Jo Buckberry. 


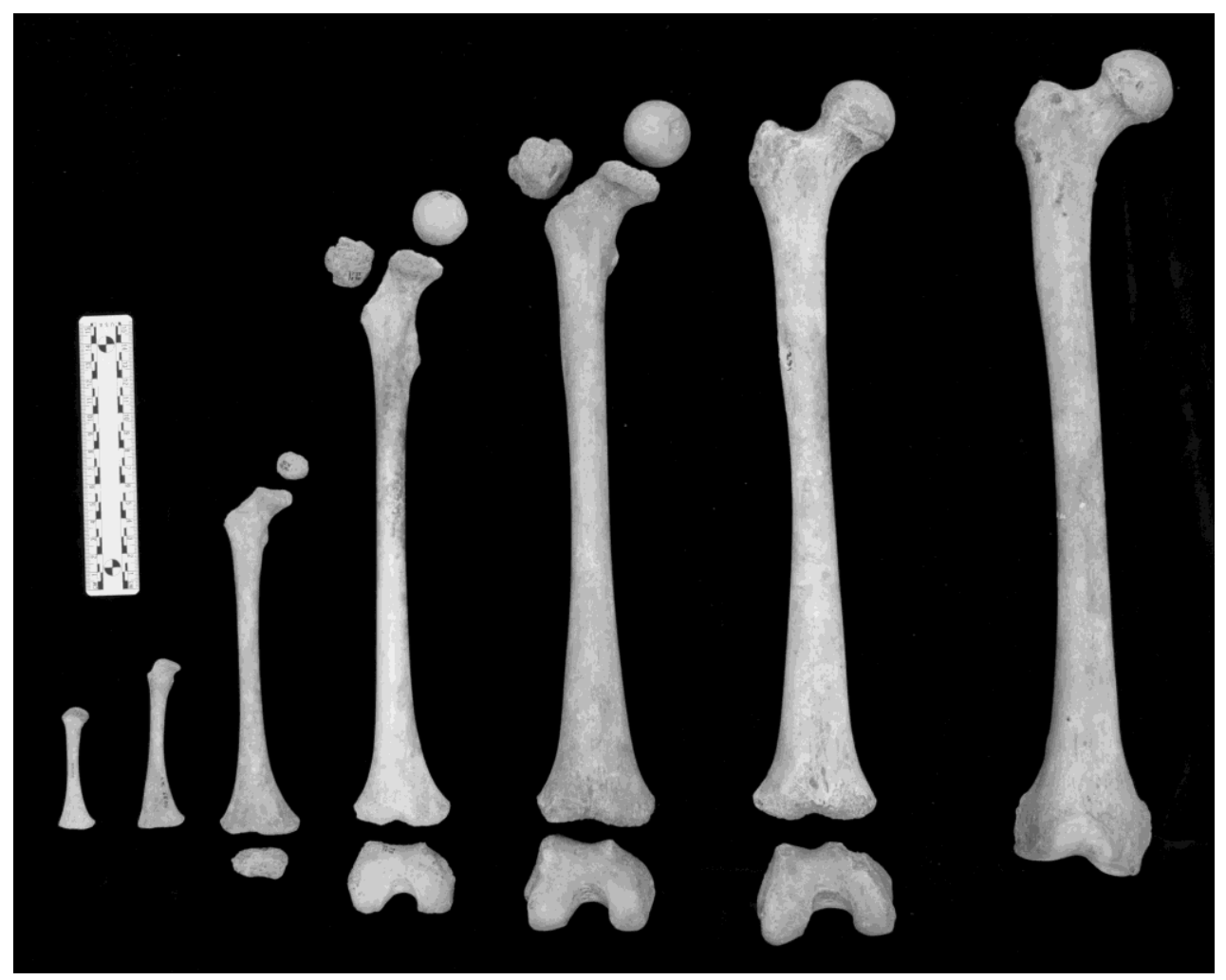

Figure 3.3. Sequence of development of the femur, from neonate on the left to adult on the right, showing appearance and then fusion of epiphyses and apophyses. ( Jo Buckberry.

The appearance of ossification centres can also be used to estimate age (Scheuer and Black 2000a); however, these are often very small and are frequently lost during excavation. When ossification centres are recovered, it can be difficult to identify them with confidence due to a lack of diagnostic features during early stages of formation. In practical terms, the appearance of ossification centres is rarely used to estimate age in 
archaeological populations, as it is usually impossible to ascertain whether the absence of particular centres was real or an artefact of the recovery process. Exceptions occur where remains are partially mummified. Here radiographs can be used to identify which ossification centres are present. The wrist/hand is a particularly diagnostic area, with the eight carpals appearing between birth and the ages of 13 (for girls) or 15 (for boys), with the fusion of the distal radius and ulna extending this range to 16-17 years (Greulich and Pyle 1959; Cameriere et al. 2012).

\section{Bone size}

Age estimates from bone size (most frequently estimated from long bone lengths) rely on the assumption that chronological age is directly related to height/body size, and hence bone length/size. Whilst there is a general relationship between the two, height will vary amongst children within a given year group. However, on average, a group of older children will be taller than a group of younger children. Bone growth allows non-adult age to be estimated from long bone lengths; however, it gets increasingly inaccurate when applied to older children.

Skeletal growth is influenced by genetic inheritance, disease, and nutritional status (which in turn are linked to socioeconomic status). Once an infant has been weaned it becomes much more susceptible to external stressors. Those affected by under- or malnutrition and disease are likely to 
exhibit a slower rate of bone growth and delayed skeletal development (Eveleth and Tanner 1990; Scheuer and Black 2000a; Mays, this volume). Long bone length has been shown to be more affected by external factors than epiphyseal fusion and especially dental development, which appears to be unaffected (Lewis and Garn 1960; Cardoso 2007; Conceição and Cardoso 2011; Elamin and Liversidge 2013). Significantly, the skeletons of children recovered from archaeological sites are, by definition, less healthy than those who survived to adulthood. Many studies have shown that age estimates derived from long bone lengths are younger than those estimated from the level of dental development in the same individual (e.g. Hoppa 1992; Schillaci et al. 2011: fig. 2), and that this disparity increases with increasing age. Applying modern growth standards (e.g. Maresh 1970) to archaeological material will usually underestimate the age of non-adults (Figure 3.5), therefore age estimates derived from long bone lengths should be used with caution; instead emphasis should be placed on dental age estimates, which have been shown to be less influenced by external factors such as poor nutrition and/or prolonged ill health. Where dental age estimates cannot be obtained, it is possible to use population-specific standards created using large samples of non-adults' skeletons with both dental ages and long bone lengths (e.g. Primeau et al. 2012, 2016). Long bone length and other bone dimensions should ideally only be used to 
estimate age in the very young, or where no other indicators of age can be observed. Comparison of estimated age from dental development and long bone length provides significant information about rates of growth in the past (see Mays, this volume).

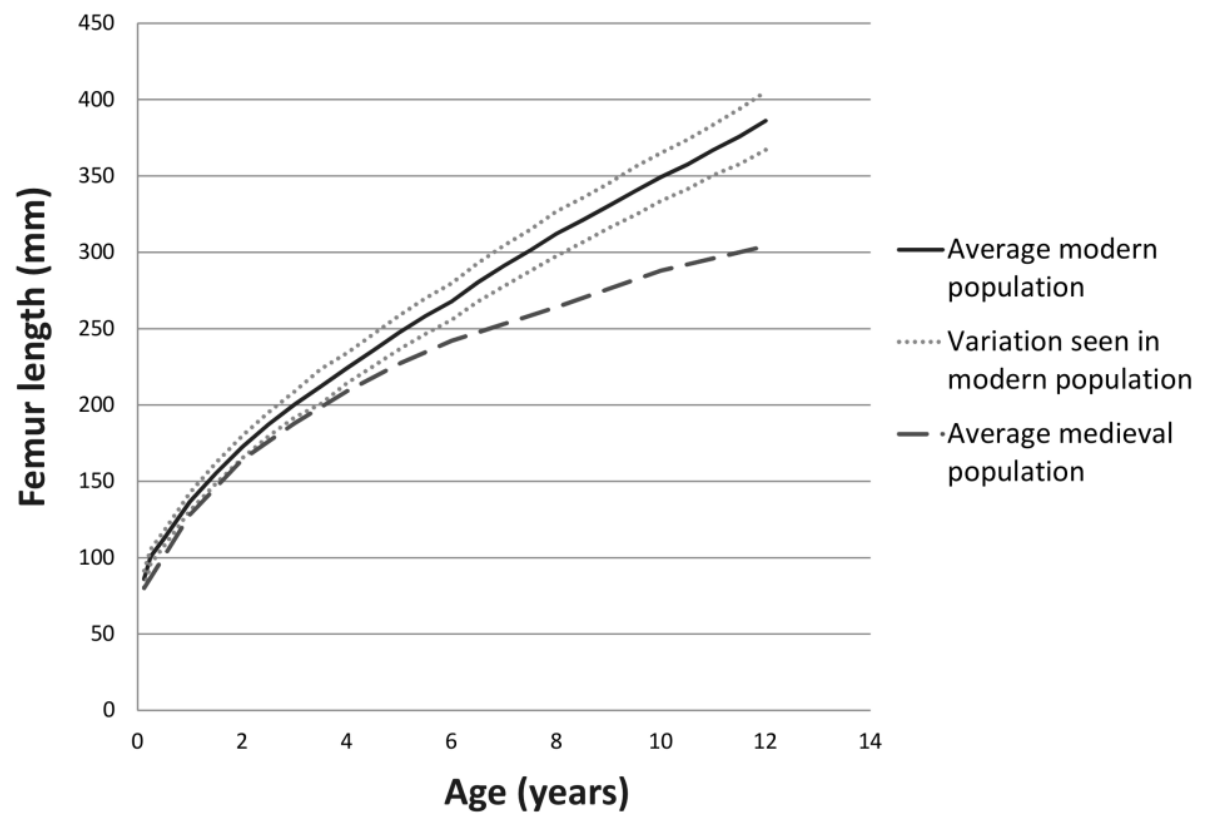

Figure 3.4. Comparison of average femur length of individuals of different ages for modern and archaeological populations. Modern data from Maresh (1970); Medieval data (Raunds) from Hoppa (1992).

Foetal and neonatal age estimation from bone size

Bone growth appears to be much more constant cross-culturally for individuals under one year of age than for older children, probably reflecting the fact that once weaned, children are far more susceptible to the 
external pressures that influence growth (Hoppa 1992). This allows the age of foetuses and infants to be estimated from bone size with higher degrees of accuracy than for older children.

István Fazekas and F. Kósa (1978) collected osteometric data from a series of modern foetal skeletons. They used the linear correlation between foetal crown-heel length and age to create age estimation standards for 67 measurements on 37 bones. They found that the long bones, mandible, and clavicle provided the most accurate age estimates, but that any bone could be used to estimate age (Kósa 1989). Scheuer, Musgrave, and Evans (1980) found that accuracy was increased if age estimations were made directly from bone length rather than via crown-heel length. Their study of modern British material included perinatal infants, thus increasing the range of age estimates that could be obtained from the long bones. They found that most cases fell very close to their regression lines (i.e. there was little spread or variability), and hence concluded that the regression equations could be used to estimate age. The authors cautioned that these equations were population-specific, and that due consideration of this should be given to any age estimates obtained using this method for different populations (Scheuer, Musgrave, and Evans 1980). 
Rebecca Gowland and Andrew Chamberlain (2002) used Bayesian statistics to better understand the influence that the variation about the mean reported by Scheuer and colleagues (1980) would have on perinatal age estimation in Romano-British cemeteries, addressing previous claims of evidence of infanticide at rural Romano-British sites (Mays 1993). They found that when the degree of spread was taken into consideration using prior probabilities, biases in the age distributions produced by the age estimation method were removed, and no peak indicative of infanticide was evident (Gowland and Chamberlain 2002). While evidence for infanticide in Roman Britain is still debated (Mays 2003; Mays and Eyers 2011; Bonsall 2013), the study by Gowland and Chamberlain (2002) suggests that error margins need to be included in age estimates from long bone length to allow for variation about the mean.

Overall, age estimates for non-adults should be made using dental development wherever possible, with epiphyseal and apophyseal fusion for all age groups, and long bone lengths for foetal and neonate remains, also providing accurate age estimates. The lengths of long bones can be used to give an indication of age, but if modern standards are used, they are likely to underestimate age. If possible, methods developed on appropriate reference collections (ideally geographically and temporally similar, although the latter will always pose a problem) should be utilized. Age 
estimates should acknowledge variation in the ageing process between individuals, with ages given as age ranges rather than as point estimates. 'Most likely' and 'cannot be excluded' age ranges are often utilized in forensic anthropology (Lynnerup et al. 2008: 242.e5). The use of similar ranges may help raise awareness of the imprecision of age estimates from skeletal remains, although this is less of a problem for non-adults compared with adult skeletons (Buckberry 2015).

\section{Assessment of sex}

Biological sex is determined by the presence or absence of the $\mathrm{Y}$ chromosome $(\mathrm{XY}=$ males, $\mathrm{XX}=$ females for most individuals $)$. The secretion of male or female hormones in sufficiently high quantities causes the body to develop male or female characteristics, which can vary in their degrees of expression during life. Studies have shown that the female phenotype is the norm, and that males develop male physical features due to the presence of male hormones during gestation (Wilson, George, and Griffin 1981). These sex differences manifest themselves in both soft tissues and eventually in bone, and the latter can be used to assess the sex of skeletons (Mays and Cox 2000).

\section{Assessing non-adult sex}

The levels of hormones secreted by the body vary throughout life. The increase in the levels of androgen during puberty cause males to develop 
male physical features (Mays and Cox 2000), increasing levels of sexual dimorphism, and allowing us to estimate adult sex with high levels of accuracy. Prior to puberty, however, sex hormone levels are low, giving rise to very low levels of sexual dimorphism and making assessment of childhood sex very difficult. The exception to this is foetal sex, as testosterone levels rise in males from about eight weeks in utero and are maintained until birth; arguably, this might result in a higher level of sexual dimorphism in neonatal skeletons than for other non-adults (Mays and Cox 2000).

Methods of non-adult sex assessment have focused on the morphological differences in the ilia, mandible, and facial bones (Weaver 1980; Schutkowski 1993; Molleson, Cruse, and Mays 1998; Loth and Henneberg 2001). The levels of sexual dimorphism observed in non-adults are less dramatic than those evident in adult remains, and are less evident in populations where lower levels of sexual dimorphism is observed in adults (Loth and Henneberg 2001); this makes reliable recording of the traits more dependent on the experience of the observer. Some studies have found reliability of sex assessment for these traits is similar to that reported for adult skeletons (Schutkowski 1993; Sutter 2003); others have found levels of accuracy to be much lower (Vlak, Roksandic, and Schillaci 2008; Wilson, MacLeod, and Humphrey 2008). Levels of sexual dimorphism 
have been shown to vary at different ages, and it has been argued that some of the morphological features used to assess non-adult sex have a higher correlation with increasing age than with biological sex (Vlak, Roksandic, and Schillaci 2008). Metrical and geometric methods of sex assessment have produced lower accuracy levels, as low as 54 to 60 per cent (Schutkowski 1987; Holcomb and Konigsberg 1995). In addition, metrical methods of sex assessment are known to be population-specific, even in adults. Once individuals hit adolescence, the sexually dimorphic features of the pelvis begin to develop adult form, and can be used tentatively for sex assessment; features of the pubic bone are especially useful in this regard, with a precursor of the highly diagnostic ventral arc being present in females as young as 14 years old, but more commonly observed by 20 years (Sutherland and Suchey 1991).

Teeth are generally larger in males than females; however, like all metrical methods of sex assessment, tooth size will be population-specific. In the case of permanent teeth, which do not change in size once developed (beyond the loss of crown height due to dental wear), the measurements of adult teeth can be used to develop population-specific standards for older children, whose permanent tooth crowns begin to develop in the first few years of life (Hillson 1996). One problem with this approach is that smaller children are more likely to die prior to adulthood (see discussion above; 
and Mays, this volume). It has been suggested that if these children also had stunted growth in their teeth, then there could be a bias towards the female sex using this approach (Mays 2010). While the rate of tooth formation is unlikely to be affected by external environmental forces (Lewis and Garn 1960; Elamin and Liversidge 2013), the extent to which this affects tooth size is unclear.

Sex can be assessed using the analysis of DNA, providing DNA has survived the burial environment and samples have not been contaminated by the DNA of anyone who has handled the remains (Brown 2000; Smith et al. 2001). As biological sex is determined by the presence/absence of the $Y$ chromosome, the presence/absence of the $\mathrm{Y}$ chromosome in ancient DNA can be used to determine whether an individual is male or female respectively (Brown 2000). While this expensive approach is unlikely to be utilized for sexually dimorphic adult remains, there is great potential for investigating the sex of non-adults, particularly now the costs of aDNA analysis are reducing. Indeed, aDNA analysis has been used to investigate if male-preferential infanticide was practised during the Roman period (Faerman et al. 1998; Mays and Faerman 2001; Hassan et al. 2014); however, the results were limited by the levels of DNA survival in the samples studied. 
At present, the methods used to investigate the sex of non-adult remains are fraught with concerns over reliability. While some appear to work well on some populations, the current standards cannot be used universally. At present, many scholars prefer not to attempt sex assessment prior to the later teenage years (Lewis 2007; Scheuer and Black 2000b: 15). This difficulty in assessing sex adds uncertainty to age estimation, as males and females generally have different rates of growth and development.

\section{Summary}

Overall, the methods used to assess the age of non-adults are well understood, and have been shown to have good levels of accuracy. This is particularly true for dental development. Thus, the age of non-adults can be estimated with a high degree of confidence, usually to within a few years. Sex assessment, on the other hand, remains problematic, but seems to be more successful for populations with marked sexual dimorphism amongst adults. If applied at all, sex assessment methods should be used under carefully controlled conditions and with a degree of caution.

\section{References}

AlQahtani, S. J., Hector, M. P., and Liversidge, H. M. (2010). 'Brief Communication: The London Atlas of Human Tooth Development 
and Eruption'. American Journal of Physical Anthropology, 142/3: 481-90.

AlQahtani, S. J., Hector, M. P., and Liversidge, H. M. (2014). 'Accuracy of Dental Age Estimation Charts: Schour and Massler, Ubelaker, and the London Atlas'. American Journal of Physical Anthropology, 154/1: 70-8.

Anderson, D. L., Thompson, G. W., and Popovitch, F. (1976). 'Age of Attainment of Mineralization Stages of the Permanent Dentition'. Journal of Forensic Sciences, 21: 191-200.

Bonsall, L. (2013). 'Infanticide in Roman Britain: A Critical Review of the Osteological Evidence'. Childhood in the Past, 6/2: 72-88.

Brown, K. A. (2000). ‘Ancient DNA Applications in Human Osteoarchaeology: Achievements, Problems and Potential', in M. Cox and S. Mays (eds), Human Osteology in Archaeology and Forensic Medicine. London: Greenwich Medical Media Ltd, 45573.

Buckberry, J. (2015). 'The (Mis)Use of Adult Age Estimates in Osteology'. Annals of Human Biology, 42/4: 323-31.

Buikstra, J. and Ubelaker, D. H. (1994). Standards for Data Collection from Human Skeletal Remains. Fayetteville, AR: Arkansas Archeological Survey. 
Cameriere, R., De Luca, S., Biagi, R., Cingolani, M., Farronato, G., and Ferrante, L. (2012). 'Accuracy of Three Age Estimation Methods in Children by Measurements of Developing Teeth and Carpals and Epiphyses of the Ulna and Radius'. Journal of Forensic Sciences, 57/5: 1263-70.

Cardoso, H. F. V. (2007). 'Environmental Effects on Skeletal Versus Dental Development: Using a Documented Subadult Skeletal Sample to Test a Basic Assumption in Human Osteological Research'. American Journal of Physical Anthropology, 132/2: $223-33$.

Conceição, E. L. N. and Cardoso, H. F. V. (2011). 'Environmental Effects on Skeletal Versus Dental Development Ii: Further Testing of a Basic Assumption in Human Osteological Research'. American Journal of Physical Anthropology, 144/3: 463-70.

Cox, M. (2000). 'Ageing Adults from the Skeleton', in M. Cox and S. Mays (eds), Human Osteology in Archaeology and Forensic Medicine. London: Greenwich Medical Media Ltd, 61-81. Crawford, S. (1991). 'When Do Anglo-Saxon Children Count?'. Journal of Theoretical Archaeology, 2: 17-24. 
Demirjian, A. and Goldstein, H. (1976). 'New Systems for Dental Maturity Based on Seven and Four Teeth'. Annals of Human Biology, 3: $411-21$.

Demirjian, A., Goldstein, H., and Tanner, J. M. (1973). 'A New System of Dental Age Assessment'. Human Biology, 45: 211-27.

Elamin, F. and Liversidge, H. M. (2013). 'Malnutrition Has No Effect on the Timing of Human Tooth Formation'. PloS One, 8/8: e72274.

Eveleth, P. B. and Tanner, J. M. (1990). Worldwide Variation in Human Growth. Cambridge: Cambridge University Press.

Faerman, M., Bar-Gal, G. K., Filon, D., Greenblatt, C. L., Stager, L., Oppenheim, A., and Smith, P. (1998). 'Determining the Sex of Infanticide Victims from the Late Roman Era through Ancient DNA Analysis'. Journal of Archaeological Science, 25/9: 861-5.

Fazekas, I. G. and Kósa, F. (1978). Forensic Fetal Osteology. Budapest: Akadémiai Kiadó.

Garn, S. M., Nagy, J. M., Sandusky, S. T., and Trowbridge, F. (1973). 'Economic Impact on Tooth Emergence'. American Journal of Physical Anthropology, 39: 233-8.

Gowland, R. (2006). 'Ageing the Past: Examining Age Identity from Funerary Evidence', in R. Gowland and C. Knüsel (eds), Social Archaeology of Funerary Remains. Oxford: Oxbow, 143-54. 
Gowland, R. and Chamberlain, A. T. (2002). 'A Bayesian Approach to Ageing Perinatal Skeletal Material from Archaeological Sites: Implications for the Evidence for Infanticide in Roman-Britain'. Journal of Archaeological Science, 29/6: 677-85.

Greulich, W. and Pyle, S. I. (1959). Radiographic Atlas of Skeletal Development of the Hand and Wrist. Stanford, CA: Stanford University Press.

Hassan, N. A-M., Brown, K. A., Eyers, J., Brown T. A., and Mays, S. (2014). 'Ancient DNA Study of the Remains of Putative Infanticide Victims from the Yewden Roman Villa Site at Hambleden, England'. Journal of Archaeological Science 43: 192-7.

Hillson, S. (1996). Dental Anthropology. Cambridge: Cambridge University Press.

Holcomb, S. and Konigsberg, L. W. (1995). 'Statistical Study of Sexual Dimorphism in the Human Fetal Sciatic Notch'. American Journal of Physical Anthropology, 97/2: 113-25.

Hoppa, R. D. (1992). 'Evaluating Human Skeletal Growth: An AngloSaxon Example'. International Journal of Osteoarchaeology, 2/4: $275-88$. 
Kósa, F. (1989). ‘Age Estimation from the Fetal Skeleton', in M. Y. İşcan (ed.), Age Markers in the Human Skeleton. Springfield, IL: Thomas, $21-54$.

Lewis, A. B. and Garn, S. M. (1960). 'The Relationship between Tooth Formation and Other Maturational Factors'. The Angle Orthodontist, 30: 70-7.

Lewis, M. (2007). The Bioarchaeology of Children. Cambridge: Cambridge University Press.

Liversidge, H. M. (1994). 'Accuracy of Age Estimation from Developing Teeth of a Population of Known Age'. International Journal of Osteoarchaeology, 4/1: 37-46.

Loth, S. R. and Henneberg, M. (2001). ‘Sexually Dimorphic Mandibular Morphology in the First Few Years of Life'. American Journal of Physical Anthropology, 115/2: 179-86.

Lynnerup, N., Belard, E., Buch-Olsen, K., Sejrsen, B., and DamgaardPedersen, K. (2008). 'Intra- and Interobserver Error of the Greulich-Pyle Method as Used on a Danish Forensic Sample'. Forensic Science International, 179: 242.e1-e6.

Maresh, M. M. (1970). ‘Measurements from Roentgenograms', in R. W. McCammon (ed.), Human Growth and Development. Springfield, IL: Charles C. Thomas, 157-200. 
Mays, S. (1993). 'Infanticide in Roman Britain'. Antiquity, 67/257: 883-8.

Mays, S. (2003). 'Comment On "A Bayesian Approach to Ageing Perinatal Skeletal Material from Archaeological Sites: Implications for the Evidence for Infanticide in Roman Britain” By R. L. Gowland and A. T. Chamberlain'. Journal of Archaeological Science, 30/12: 1695-700.

Mays, S. (2010). The Archaeology of Human Bones. London: Routledge. Mays, S. and Cox, M. (2000). 'Sex Determination in Skeletal Remains', in M. Cox and S. Mays (eds), Human Osteology in Archaeology and Forensic Science. London: Greenwich Medical Media, 117-30.

Mays, S. and Eyers, J. (2011). 'Perinatal Infant Death at the Roman Villa Site at Hambleden, Buckinghamshire, England'. Journal of Archaeological Science, 38/8: 1931-8.

Mays, S. and Faerman, M. (2001). 'Sex Identification in Some Putative Infanticide Victims from Roman Britain Using Ancient DNA'. Journal of Archaeological Science, 28/5: 555-9.

Molleson, T., Cruse, K., and Mays, S. (1998). 'Some Sexually Dimorphic Features of the Human Juvenile Skull and Their Value in Sex Determination in Immature Skeletal Remains'. Journal of Archaeological Science, 25/8: 719-28. 
Moorrees, C. F. A., Fanning, E. A., and Hunt, E. E. (1963a). ‘Age

Variation of Formation Stages for Ten Permanent Teeth'. Journal of Dental Research, 42/6: 1490-501.

Moorrees, C. F. A., Fanning, E. A., and Hunt, E. E. (1963b). 'Formation and Resorption of Three Deciduous Teeth in Children'. American Journal of Physical Anthropology, 21/2: 205-13.

Primeau, C., Friis, L., Sejrsen, B., and Lynnerup, N. (2012). 'A Method for Estimating Age of Danish Medieval Sub-Adults Based on Long Bone Length'. Anthropologischer Anzeiger, 69/3: 317-33.

Primeau, C, Friis, L, Sejrsen, B and Lynnerup, N, (2016) 'A method for estimating age of medieval sub-adults from infancy to adulthood based on long bone length' American Journal of Physical Anthropology 159(1): 135-145.

Redfield, A. (1970). 'A New Aid to Aging Immature Skeletons:

Development of the Occipital Bone'. American Journal of Physical Anthropology, 33/2: 207-20.

Saunders, S. R., DeVito, C., Herring, A., Southern, R., and Hoppa, R. D. (1993). 'Accuracy Tests of Tooth Formation Age Estimations for Human Skeletal Remains'. American Journal of Physical Anthropology, 92/2: 173-88. 
Schaefer, M. C. (2008). 'A Summary of Epiphyseal Union Timings in Bosnian Males'. International Journal of Osteoarchaeology, 18/5: $536-45$.

Scheuer, L. and Black, S. (2000a). 'Development and Ageing of the Juvenile Skeleton', in M. Cox and S. Mays (eds), Human Osteology in Archaeology and Forensic Medicine. London: Greenwich Medical Media Ltd, 9-21.

Scheuer, L. and Black, S. (2000b). Developmental Juvenile Osteology. London: Academic Press.

Scheuer, L., Musgrave, J. H., and Evans, S. P. (1980). 'The Estimation of Late Fetal and Perinatal Age from Long Bone Length by Linear and Logarithmic Regression'. Annals of Human Biology, 7/3: 257-65.

Schillaci, M. A., Nikitovic, D., Akins, N. J., Tripp, L., and Palkovich, A. M. (2011). 'Infant and Juvenile Growth in Ancestral Pueblo Indians'. American Journal of Physical Anthropology, 145/2: 31826.

Schour, I. and Massler, M. (1941). 'The Development of the Human Dentition'. Journal of the American Dental Association, 20: 379427. 
Schutkowski, H. (1987). 'Sex Determination of Fetal and Neonate

Skeletons by Means of Discriminant Analysis'. International Journal of Anthropology, 2/4: 347-52.

Schutkowski, H. (1993). ‘Sex Determination of Infant and Juvenile Skeletons: I. Morphological Features'. American Journal of Physical Anthropology, 90: 199-205.

Smith, B. H. (1991). 'Standards of Human Tooth Formation and Dental Age Assessment', in M. A. Kelley and C. S. Larsen (eds), Advances in Dental Anthropology. New York, NY: Wiley Liss Inc., 143-68.

Smith, C. I., Chamberlain, A. T., Riley, M. S., Cooper, A., Stringer, C. B., and Collins, M. J. (2001). 'Not Just Old but Old and Cold?'. Nature, 410: 771-2.

Sutherland, L. D. and Suchey, J. M. (1991). 'Use of the Ventral Arc in Pubic Sex Determination'. Journal of Forensic Sciences, 36: 50111.

Sutter, R. C. (2003). 'Nonmetric Subadult Skeletal Sexing Traits: I. A Blind Test of the Accuracy of Eight Previously Proposed Methods Using Prehistoric Known-Sex Mummies from Northern Chile'. Journal of Forensic Sciences, 48/5: 927-35.

Ubelaker, D. H. (1989). Human Skeletal Remains: Excavation, Analysis, Interpretation. Washington DC: Taraxacum. 
Vlak, D., Roksandic, M., and Schillaci, M. A. (2008). 'Greater Sciatic Notch as a Sex Indicator in Juveniles'. American Journal of Physical Anthropology, 137/3: 309-15.

Weaver, D. S. (1979). 'Application of the Likelihood Ratio Test to Age Estimation Using the Infant and Child Temporal Bone'. American Journal of Physical Anthropology, 50/2: 263-9.

Weaver, D. S. (1980). 'Sex Differences in the Ilia of a Known Sex and Age Sample of Fetal and Infant Skeletons'. American Journal of Physical Anthropology, 52/2: 191-5.

Whittaker, D. (2000). 'Ageing from the Dentition', in M. Cox and S. Mays (eds), Human Osteology in Archaeology and Forensic Medicine. London: Greenwich Medical Media Ltd, 83-99.

Wilson, J. D., George, F. W., and Griffin, J. E. (1981). 'The Hormonal Control of Sexual Development'. Science, 211: 1278-84.

Wilson, L. A., MacLeod, N., and Humphrey, L. T. (2008). 'Morphometric Criteria for Sexing Juvenile Human Skeletons Using the Ilium'. Journal of Forensic Sciences, 53/2: 269-78.

${ }^{1}$ Osteologists do not determine age or sex. The word 'determine' hides the uncertainty that is inherent when inferring age or sex from skeletal 
remains. Thus, the phrasing age estimation and sex assessment are preferred.

${ }^{2}$ In this shorthand notation, a tooth is referred to by the first letter(s) of its name (incisor, canine, premolar, or molar). A number is used to indicate its position in the jaw, with subscript denoting a mandibular tooth and superscript indicating a maxillary tooth. Hence $\mathrm{M}_{2}$ refers to the lower second molar. 